\title{
Characterization and Antioxidant Activity of Released Exopolysaccharide from Potential Probiotic Leuconostoc mesenteroides LM187
}

\author{
Qing Zhang*, Jie Wang, Qing Sun, Shu-Ming Zhang, Xiang-Yang Sun, Chan-Yuan Li, \\ Miao-Xin Zheng, Wen-Liang Xiang, and Jie Tang*
}

Key Laboratory of Food Biotechnology, College of Food and Bioengineering, Xihua University, Chengdu 610039, Sichuan, P.R. China

\begin{abstract}
A released exopolysaccharide (rEPS)-producing strain (LM187) with good acid resistance, bile salt resistance, and cholesterol-lowering properties was isolated from Sichuan paocai and identified as Leuconostoc mesenteroides subsp. mesenteroides. The purified rEPS, designated as rEPS414, had a uniform molecular weight of $7.757 \times 10^{5} \mathrm{Da}$. Analysis of the monosaccharide composition revealed that the molecule was mainly composed of glucose. The Fourier transform-infrared spectrum showed that rEPS414 contained both $\alpha$-type and $\beta$-type glycosidic bonds. ${ }^{1} \mathrm{H}$ and ${ }^{13} \mathrm{C}$ nuclear magnetic resonance spectra analysis showed that the purified rEPS contained arabinose, galactose, and rhamnose, but less uronic acid. Scanning electron microscopy demonstrated that the exopolysaccharide displayed a large number of scattered, fluffy, porous cellular network flake structures. In addition, rEPS414 exhibited strong in vitro antioxidant activity. These results showed that strain LM187 and its rEPS are promising probiotics with broad prospects in industry.
\end{abstract}

Keywords: Characterization, released exopolysaccharide, Leuconostoc mesenteroides, antioxidant

Received: March 31, 2021 Accepted: June 8, 2021

First published online: June 10, 2021

${ }^{*}$ Corresponding authors Q. Zhang Phone: +86-28-87720552 Fax: +86-28-87720552 E-mail: biozhangq@163.com J. Tang

E-mail: tangjie1225@mail.xhu. edu.cn

pISSN 1017-7825 elSSN 1738-8872

Copyright(C) 2021 by The Korean Society for Microbiology and Biotechnology

\section{Introduction}

Lactic acid bacteria (LAB) are the principal source of probiotic strains and are part of the natural flora in the human gastrointestinal environment [1]. Based on their long history of use in a wide array of food products, they are regarded as safe according to the Generally Recognized As Safe list from the U.S. Food and Drug Administration [2]. As one of the most important functional components of LAB metabolic products, exopolysaccharides (EPS) are economically important because they can impart positive functional effects to food and benefit health $[3,4]$. In recent years, EPS have been found to possess numerous beneficial biological effects, including anti-inflammatory $[5,6]$, antioxidant $[7,8]$, immunomodulatory $[9,10]$, and antitumor activities $[11,12]$.

EPS can be classified as homopolysaccharides or heteropolysaccharides according to whether they are composed of one or more types of sugars [13]. Structural factors such as molecular weight, monosaccharide composition, and chemical groups are widely accepted determinants of EPS physiological activities [14]. Therefore, the search for novel EPS-producing strains with ideal functional characteristics has become a focus of current research [15].

Sichuan paocai, or Chinese pickle, is a widely used traditional Chinese food that is rich in LAB, which are the dominant microorganisms under fermentation conditions [16]. Liu et al. [17] screened an EPS-producing strain of Lactobacillus plantarum HY isolated from Sichuan paocai, and purified HY EPS showed considerable antioxidant and alpha-amylase inhibitory activities. In addition, Hu et al. [18] screened a strain of Bacillus sp. S-1 from Sichuan paocai, and the EPS produced by this strain was found to effectively prevent oxidative damage. Leuconostoc mesenteroides, the most widely distributed type of LAB, has been implicated in human health [19]. However, few studies have focused on L. mesenteroides isolated from Sichuan paocai.

In this study, we screened 13 released EPS (rEPS)-producing strains of LAB from Sichuan paocai, determined the rEPS-producing ability of the strains by using the phenol-sulfuric acid method, and identified strain LM187 as showing the highest rEPS yield. In addition, the strain showed good acid and bile salt resistance, and may lower cholesterol. To explore the potential applications of rEPS, we isolated and identified the rEPS produced by strain LM187 and investigated their antioxidant activities in vitro. 


\section{Materials and Methods}

\section{Microorganism and Culture Conditions}

Strain L. mesenteroides LM187 was isolated from a sample of traditional Sichuan paocai and showed the highest yield among 13 strains with the ability to produce rEPS. MRS liquid medium was used for the activation and cultivation of strain LM187. rEPS was produced in sugar production medium ( $180 \mathrm{~g}$ of sucrose, $10 \mathrm{~g}$ of peptone, 5 $\mathrm{g}$ of dipotassium phosphate, and $2 \mathrm{~g}$ of sodium chloride). The medium for selecting strain LM187 was MRS selection medium, which was prepared with the same components as MRS except that the glucose quantity was changed to $5 \mathrm{~g}$ and $50 \mathrm{~g}$ sucrose was added. MRS-Oxgall-CHOL (MOC) medium was used to measure the cholesterol-lowering ability of strain LM187 and was prepared with the same components as MRS except that 100 $\mu \mathrm{g} / \mathrm{ml}$ water-soluble cholesterol was added, followed by sterilization at $121^{\circ} \mathrm{C}$ for $15 \mathrm{~min}$.

\section{Identification of Strain LM187}

Strain LM187 was successively identified by colony morphology, Gram staining, cell morphology, physiological and biochemical tests, and 16S rRNA sequence analysis. The $16 \mathrm{~S}$ rRNA gene was amplified by PCR using primers EU27F (5'-AGAGTTTGATCCTGGCTCAG-3') and 1492R (5'-GGTTACCTTGTTACGACTT-3'). Thermal cycles were as follows: $95^{\circ} \mathrm{C}$ for $5 \mathrm{~min}, 30 \mathrm{cycles}$ of $94^{\circ} \mathrm{C}$ for $1 \mathrm{~min}, 50^{\circ} \mathrm{C}$ for $1 \mathrm{~min}$, and $72^{\circ} \mathrm{C}$ for $2 \mathrm{~min}$, and $72^{\circ} \mathrm{C}$ for $10 \mathrm{~min}$. The $16 \mathrm{~S}$ rRNA sequences were compared with those in the GenBank Nucleotide Library for sequence similarity using BLAST software (https://blast.ncbi.nlm.nih.gov/Blast.cgi). A phylogenetic tree was analyzed and constructed by the neighbor-joining method using MEGA version 5.0 software.

\section{Bioactivities of Strain LM187}

According to a report by Vinderola et al. [20], the $\mathrm{pH}$ of the human stomach is typically maintained in the range of 3.0-5.0. Therefore, in the current study, the acid resistance capability of strain LM187 was assessed. The strain was cultivated at $30^{\circ} \mathrm{C}$ until the cell concentration reached $1 \times 10^{8}$ colony-forming units $(\mathrm{CFU}) / \mathrm{ml}$, and the prepared cultures $(2.0 \%, \mathrm{v} / \mathrm{v})$ were inoculated into $100 \mathrm{ml}$ MRS broth at various $\mathrm{pH}(2.0,2.5,3.0,3.5,4.0,5.0$, or 6.86) and incubated at $30^{\circ} \mathrm{C}$ for $8 \mathrm{~h}$. The viable bacterial count was determined according to GB4789.2-2016, and the survival rate was calculated as follows:

Survival rate $(\%)=\left(\log \mathrm{N}_{1} / \log \mathrm{N}_{0}\right) \times 100 \%$,

where $\mathrm{N}_{1}$ is the number of viable bacterial colonies after acid-resistant treatment and $\mathrm{N}_{0}$ is the number of viable colonies treated with MRS liquid medium at $\mathrm{pH} 6.86$.

The bile salt resistance of strain LM187 was determined by inoculating the culture $(2.0 \%, \mathrm{v} / \mathrm{v})$ into MRS medium containing different bile salt concentrations from $0 \%$ to $0.3 \%$, followed by incubation at $30^{\circ} \mathrm{C}$ for $12 \mathrm{~h}$ and colony counting.

To examine the cholesterol-lowering ability of LM187 [21], mixtures of 2, 5, 10, 12, 15, or $20 \mu \mathrm{g} / \mathrm{ml}$ cholesterol alcohol solution and MRS liquid medium were prepared. The total cholesterol concentration in the supernatant was determined using the $O$-phthaldehyde method [22]. Prepared cultures of the strain $(2.0 \%, \mathrm{v} / \mathrm{v})$ were inoculated into $10 \mathrm{ml} \mathrm{MOC}$ medium and incubated at $30^{\circ} \mathrm{C}$ for $12 \mathrm{~h}$. The control sample contained uninoculated MOC medium, and the ability of the strain to clear cholesterol was calculated according to the standard curve, $\mathrm{y}=0.0354 \mathrm{x}-0.0141\left(\mathrm{R}^{2}=0.999\right)$ as follows:

Cholesterol clearance rate $(\%)=\left[\left(\mathrm{C}_{0}-\mathrm{C}_{1}\right) / \mathrm{C}_{0}\right] \times 100 \%$,

where $\mathrm{C}_{0}$ is the initial cholesterol content and $\mathrm{C}_{1}$ is the cholesterol content of the supernatant.

\section{Preparation and Purification of rEPS}

Fresh sugar production medium was inoculated (2\%,v/v) with LM187 culture suspension and incubated at $30^{\circ} \mathrm{C}$ for $36 \mathrm{~h}$. rEPS was prepared as described by Savadogo et al. [23] with some modifications. After bacterial growth, the cells were pelleted by centrifugation at $10,000 \times g$ for $10 \mathrm{~min}$ at $4^{\circ} \mathrm{C}$, and the cell-free supernatant was precipitated by mixing with a three-fold volume of absolute cold ethanol. The crude rEPS was allowed to stand overnight at $4^{\circ} \mathrm{C}$, after which the sample was centrifuged at $10,000 \times g$ for $15 \mathrm{~min}$. This step was repeated several times. rEPS in strain LM187 was quantified by the phenol sulfuric acid method using glucose as a standard, which was detected at $490 \mathrm{~nm}$, and a standard curve was used to calculate EPS content [24]. The standard curve was $\mathrm{y}=0.0073 \mathrm{x}+0.0591\left(\mathrm{R}^{2}=0.9979\right)$.

rEPS was purified using the method described by Wang et al. [25] with some modifications. Papain solution $(0.2 \mathrm{ml}, 10 \mathrm{mg} / \mathrm{ml})$ was added to the crude rEPS solution, the $\mathrm{pH}$ was adjusted to 6.5 , and the solution was placed in a $55^{\circ} \mathrm{C}$ water bath for $4 \mathrm{~h}$. Next, $4 \%(\mathrm{w} / \mathrm{v})$ Sevag solution was added to remove the proteins. The precipitated rEPS was collected by centrifugation and maintained overnight. The resulting rEPS was dried at $90^{\circ} \mathrm{C}$, and the precipitate was dissolved in distilled water. Finally, the solution was dialyzed (cut-off $3500 \mathrm{Da}$ ) against distilled water and freeze-dried. Purified rEPS was used for subsequent analysis [26].

\section{Characterization of rEPS Fractions}

UV and infrared spectra of rEPS. The rEPS $(0.1 \mathrm{mg} / \mathrm{ml})$ was dissolved in distilled water and scanned from 200 to $400 \mathrm{~nm}$ with a UV spectrophotometer 2400 (Shanghai Sunny Hengping Scientific Instrument Co., Ltd., China) to determine the purity of the sample.

The main functional groups of the rEPS were detected by Fourier transform-infrared spectroscopy (FT-IR) 
[27]. Purified $\mathrm{rEPS}$ powder $(2 \mathrm{mg})$ was mixed with dry potassium bromide for FT-IR recording in the wavelength range of $4,000-400 \mathrm{~cm}^{-1}$.

Determination of molecular weight (Mw) of rEPS. The molecular weight and molecular weight distribution of rEPS414 were measured by gel permeation chromatography multiangle laser light scattering (GPC-MALLS). The mobile phase was $\mathrm{NaN}_{3}(0.02 \%)$ at a flow rate of $1.0 \mathrm{ml} \mathrm{min}^{-1}$, and the column temperature was $40^{\circ} \mathrm{C}$. The injection volume was $20 \mu \mathrm{l}$.

\section{Monosaccharide Components Analysis}

The monosaccharide composition of the rEPS was determined by pre-column derivatization highperformance liquid chromatography (HPLC) [28]. The purified sample (5 mg) was dissolved in $0.5 \mathrm{ml}$ of $4 \mathrm{M}$ trifluoroacetic acid and heated at $120^{\circ} \mathrm{C}$ for $2 \mathrm{~h}$ to hydrolyze the EPS into its component monosaccharides under a nitrogen atmosphere. The hydrolyzed sample of the purified rEPS fraction was dissolved in $0.5 \mathrm{ml}$ of $0.3 \mathrm{M}$ aqueous $\mathrm{NaOH}$ and $0.5 \mathrm{M} \mathrm{PMP}$ (dissolved in methanol) and incubated for $1 \mathrm{~h}$ at $70^{\circ} \mathrm{C}$. After cooling to $25^{\circ} \mathrm{C}, 0.5$ $\mathrm{ml}$ of $0.3 \mathrm{M} \mathrm{HCl}$ was added to neutralize the mixture. The resulting solution was extracted with chloroform $(0.5$ $\mathrm{ml}$ ), and the process was repeated three times. The aqueous layer was filtered through a $0.45-\mu \mathrm{m}$ membrane and subjected to HPLC analysis. Standard monosaccharides were also pre-treated according to the above steps [2].

HPLC analysis of 1-phenyl-3-methyl-5-pyrazolone (PMP) monosaccharides was carried out on an HPLC system equipped with a UV-Vis detector. Mobile phase A was $0.1 \mathrm{M}$ potassium dihydrogen phosphate ( $\mathrm{pH}$ 6.9), and mobile phase B was acetonitrile. Elution was carried out with isocratic elution using $82 \%$ mobile phase B at a flow rate of $1.0 \mathrm{ml} / \mathrm{min}$ at $25^{\circ} \mathrm{C}$. The injection volume was $10 \mu \mathrm{l}$, and the wavelength for UV detection was $245 \mathrm{~nm}$. The analytical column used was a SHISEIDO C18 $(4.6 \times 250 \mathrm{~mm}, 5 \mu \mathrm{m}$; Japan).

\section{Nuclear Magnetic Resonance Analysis}

Purified EPS (50 mg) was dissolved in $1.0 \mathrm{ml} \mathrm{D} \mathrm{D}_{2} \mathrm{O}$ and analyzed. High-resolution ${ }^{1} \mathrm{H}$ and ${ }^{13} \mathrm{C}$ nuclear magnetic resonance (NMR) spectra were recorded on an NMR spectrometer operating at a sample temperature of $25^{\circ} \mathrm{C}$.

\section{Scanning Electron Microscopy Analysis}

Scanning electron microscopy (SEM) images of purified rEPS samples were obtained after fixing the samples onto aluminium stubs and gold-sputtering. A Hitachi SU8010N field emission scanning electron microscope (Japan) was used to observe and record the representative visual field.

\section{Assay of Antioxidant Activities}

DPPH free radical scavenging assay. DPPH free radical scavenging activity was measured as described by Rai et al. [29]. Purified rEPS was dissolved in water at various concentrations $\left(0.2,0.4,0.6,0.8\right.$, and $\left.1.0 \mathrm{mg} / \mathrm{ml}^{-1}\right)$. Next, $2.0 \mathrm{ml}$ of each sample was mixed with $2.0 \mathrm{ml}$ of $0.2 \mathrm{M} \mathrm{DPPH}$-ethanol solution. The mixture was shaken well and left for $30 \mathrm{~min}$ at $25^{\circ} \mathrm{C}$ in the dark, and then measured at $517 \mathrm{~nm}$ in a UV spectrophotometer. The same concentration of ascorbic acid (vitamin C, Vc) was used as a control. The DPPH radical scavenging capability was calculated using the following formula:

Scavenging activity $(\%)=\left[1-\left(\mathrm{A}_{1}-\mathrm{A}_{2}\right) / \mathrm{A}_{0}\right] \times 100 \%$,

where $A_{0}$ is the absorbance of a mixture of $2 \mathrm{ml} \mathrm{DPPH}$ and $2 \mathrm{ml}$ distilled water, $\mathrm{A}_{1}$ is the absorbance of a mixture of $2 \mathrm{ml} \mathrm{DPPH}$ and $2 \mathrm{ml}$ purified $\mathrm{rEPS}$ solution, and $\mathrm{A}_{2}$ is the absorbance of a mixture of $2 \mathrm{ml}$ purified rEPS solution and $2 \mathrm{ml}$ ethanol.

Hydroxyl radical scavenging activity. The hydroxyl radical scavenging activity was calculated as described by $\mathrm{Xia}[30]$ with some modifications. Purified $\mathrm{rEPS}$ was dissolved in water at various concentrations $(0.2,0.4,0.6,0.8$, and $1.0 \mathrm{mg} \mathrm{ml}^{-1}$ ). Next, $2.0 \mathrm{ml}$ of each sample solution was mixed with $2.0 \mathrm{ml}$ of $6 \mathrm{mM} \mathrm{FeSO}_{4}$ and $\mathrm{H}_{2} \mathrm{O}_{2}$ solution. The mixture was shaken well and left for $10 \mathrm{~min}$, and $2.0 \mathrm{ml}$ of $6 \mathrm{mM}$ salicylic acid was added. The mixture was left for $40 \mathrm{~min}$, and the absorbance was measured at $510 \mathrm{~nm}$. The same concentration of ascorbic acid was used as a control.

Scavenging activity $(\%)=\left[1-\left(\mathrm{A}_{1}-\mathrm{A}_{2}\right) / \mathrm{A}_{0}\right] \times 100 \%$,

where $A_{0}$ is the absorbance of distilled water, $A_{1}$ is the absorbance of the sample, and $A_{2}$ is the absorbance of the sample without $\mathrm{H}_{2} \mathrm{O}_{2}$ solution.

Superoxide radical scavenging activity. The scavenging activity of superoxide anion free radicals was determined by the pyrogallol auto-oxidation method [31]. Each sample solution $(0.1 \mathrm{ml})$ was mixed with $4.5 \mathrm{ml}$ of $0.05 \mathrm{M}$ Tris- $\mathrm{HCl}\left(\mathrm{pH} \mathrm{8.2)}\right.$. The mixture was shaken well and left for $10 \mathrm{~min}$ at $25^{\circ} \mathrm{C}$. Next, $0.4 \mathrm{ml}$ of $10 \mathrm{mM}$ pyrogallol solution was added to the mixture and left for $25 \mathrm{~min}$. The reaction was stopped by adding $300 \mu \mathrm{l}$ of concentrated $\mathrm{HCl}$, and the absorbance was measured at $320 \mathrm{~nm}$. The same concentration of ascorbic acid was used as a control. Scavenging activity was determined as follows:

Scavenging activity $(\%)=\left[1-\left(\mathrm{A}_{1}-\mathrm{A}_{2}\right) / \mathrm{A}_{0}\right] \times 100 \%$,

where $A_{0}$ is the absorbance of distilled water in the mixture rather than in the sample, $A_{1}$ is the absorbance of the sample, and $\mathrm{A}_{2}$ is the absorbance of distilled water in the mixture rather than the pyrogallol. 

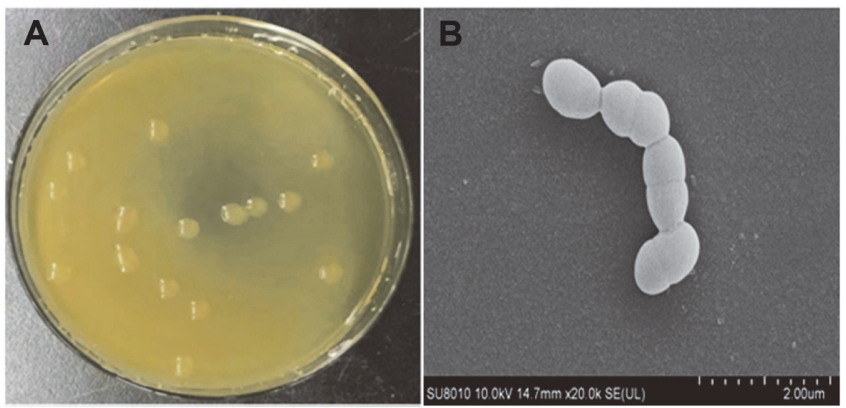

Fig. 1. Colony and cell morphological characteristics of strain LM187.

\section{Statistical Analysis}

All experiments were repeated three times and the results represented by their mean \pm SD; $p<0.05$ was considered statistically significant. Data were analyzed using SPSS 19.0 software (SPSS, Inc., USA).

\section{Results and Discussion \\ Identification of Strain LM187}

Lactic acid bacteria were screened from Sichuan paocai samples, and selected strains were inoculated on sugar production medium agar and cultured at $30^{\circ} \mathrm{C}$. Among 13 strains found to produce rEPS, strain LM187 showed the highest yield. The colony and morphological characteristics of LM187 are shown in Fig. 1. Analysis of the colony morphology (Fig. 1A) showed that the strain formed mucoid colonies on the surface of the medium, which were milky white, shiny, and had neat edges. The cells were observed as pairs or chains of cocci under a microscope (Fig. 1B), and the strain was gram-positive. Combined with physiological and biochemical tests and 16S rRNA gene phylogeny analysis (Fig. 2A), strain LM187 was suggested to belong to L. mesenteroides. However, studies have shown that $16 \mathrm{~S}$ rRNA gene sequences often show low resolution when distinguishing related species [32]. When analyzing the genetic relationship of relatives within the genus, $r p o B$ housekeeping genes give higher resolution than 16S rRNA [33]. Comparative sequencing of the $16 \mathrm{~S}$ rRNA and $r p o B$ housekeeping genes allowed for successful identification of strain LM187 as L. mesenteroides subsp. mesenteroides (Fig. 2B) (Collection number: CGMCC 7.363, GenBank accession number: MH460418).

\section{Probiotic Properties of Strain LM187}

Microorganisms used as probiotics must overcome the inhospitable conditions of the human gastrointestinal

A Leuconostoc citreum strain EFEL 2700 (CP024929)

97 Leuconostoc citreum KM20 (DQ489736)

Leuconostoc sp. C2 (CP002898)

Lactobacillus reuteri TD1 (CP006603)

71 LM187 (MH460418)

Leuconostoc mesenteroides subsp. DRC1506 (CP014611)

100 Leuconostoc mesenteroides subsp. mesenteroides ATCC 8293 (CP000414)

B

32 Leuconostoc mesenteroides subsp. DRC1506

88 LLeuconostoc mesenteroides subsp. mesenteroides ATCC 8293 (СР000414)

LM187 (MH460418)

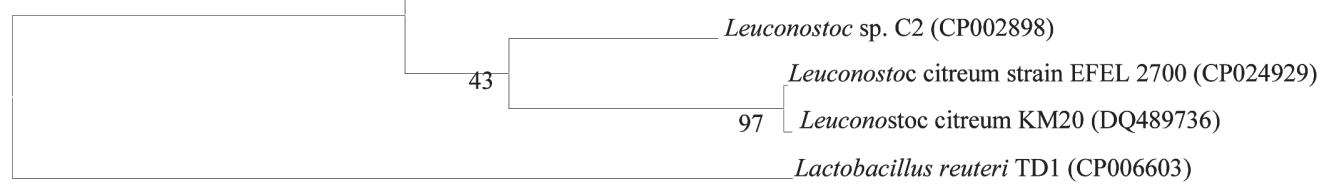

0.05

Fig. 2. Phylogenetic tree of strain LM187 based on $16 \mathrm{~S}$ rRNA (A) and $r p o B(B)$ sequences. 


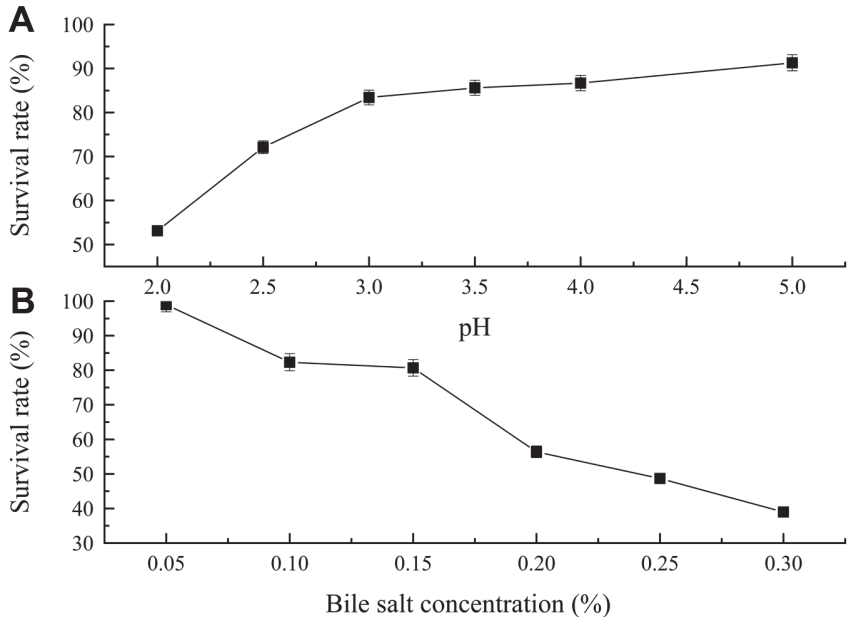

Fig. 3. Acid and bile salt tolerance tests of strain LM187.

tract [34]. To reach the gastrointestinal tract while maintaining sufficient viability, probiotic strains should be able to withstand a low $\mathrm{pH}$ and high bile salt concentrations $[34,35]$. The results of the acid resistance test of strain LM187 are shown in Fig. 3A. After $8 \mathrm{~h}$ incubation, the strain survival rate was 53.1\% (pH 2.0), indicating that LM187 can tolerate a low $\mathrm{pH}$. These results agree with the finding that the survival rate of all LAB is significantly affected by low acidity, particularly incubation at $\mathrm{pH} 2[34,36]$. Bile salt tolerance is considered as an essential property of LAB in the intestinal tract [37]. The bile salt resistance of this strain is shown in Fig. 3B. The strain survival rate was $39.0 \%$ when the bile salt concentration was $0.3 \%$, indicating strain LM187 can tolerate high concentrations of bile salts. The results for bile salt tolerance observed in this study are consistent with those reported by Nami et al. [38], who determined the survival rate of selected LAB isolated from dairy samples.

Another important characteristic of probiotic strains is their cholesterol-lowering ability. Our findings showed that the cholesterol-lowering rate of L. mesenteroides subsp. mesenteroides LM187 was 53.0\%. Similarly, Lee et al. [39] screened a strain of $L$. mesenteroides MKSR from Korean fermented vegetable kimchi, revealing a cholesterol lowering rate of 59\%. Probiotic EPS has been reported to possess hypocholesterolemic bioactivities [40]. There was an earlier report that certain EPS-producing probiotics strains could bind free bile acids thus increasing their excretion after digestion and result in the synthesis of new bile acids from cholesterol by the liver and thereby decreasing cholesterol levels [21]. Hence, rEPS-producing LM187 shows potential as a probiotic based on its comparable cholesterol-lowering ability.

\section{UV and FT-IR Spectral Analysis of rEPS}

Compared with the UV spectra of crude EPS, the UV spectra of purified rEPS showed no obvious absorption at 260 or $280 \mathrm{~nm}$, clearly indicating that rEPS414 did not contain nucleic acids or proteins.

The FT-IR spectra of purified rEPS were recorded over an absorbance range of 4,000-400 $\mathrm{cm}^{-1}$ and are shown in Fig. 4. Purified rEPS showed a broad absorption peak centered at around $3,332 \mathrm{~cm}^{-1}$, which was attributed to the intense hydroxyl group $(\mathrm{O}-\mathrm{H})$ stretching vibration [41]. The absorption peak at $2,933 \mathrm{~cm}^{-1}$ was assigned to the C-

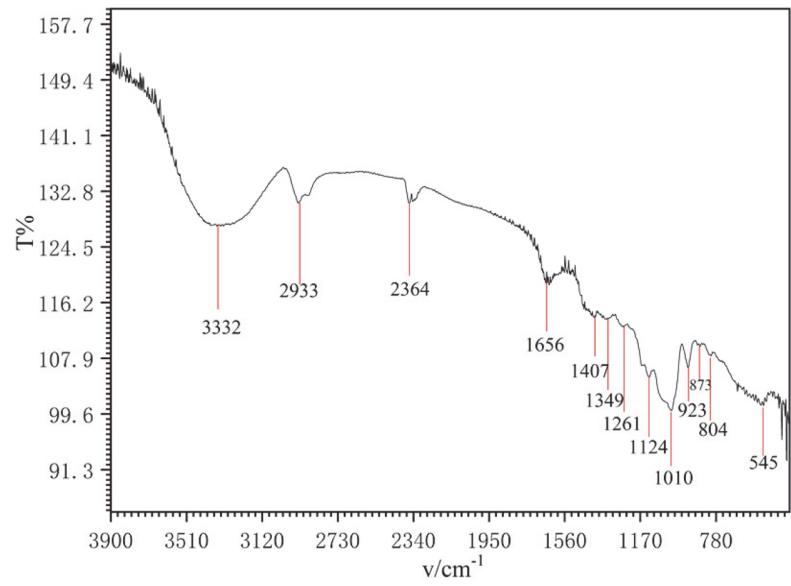

Fig. 4. FT-IR spectrum of rEPS414. 
Table 1. The results of rEPS414 by GPC-MALLS.

\begin{tabular}{lccc}
\hline \multicolumn{1}{c}{ Name (g/mol) } & $\begin{array}{c}\text { Molecular weight } \\
(\mathrm{Da})\end{array}$ & Range (g/mol) & $\begin{array}{c}\text { Molecular weight } \\
\text { distribution }(\%)\end{array}$ \\
\hline Molecular weight distribution index (Mw/Mn) & 1.571 & $189000.0-3000000.0$ & 16.2 \\
Dispersion (Mz/Mn) & 3.328 & $3000000.0-9500000.0$ & 45.0 \\
Number average molecular weight (Mn) & $4.937 \times 10^{5}$ & $9500000.0-15000000.0$ & 35.4 \\
Peak molecular weight (Mp) & $3.302 \times 10^{5}$ & $15000000.0-63335316.0$ & 3.0 \\
Weight average molecular weight (Mw) & $7.757 \times 10^{5}$ & & \\
Zaverage molecular weight $(\mathrm{Mz})$ & $1.643 \times 10^{6}$ & & \\
\hline
\end{tabular}

$\mathrm{H}$ bond, and weak absorption near $1,656 \mathrm{~cm}^{-1}$ was attributed to $\mathrm{C}=\mathrm{O}$ stretching vibration $[41,42]$. The strong absorption peak in the range of $1,410-1,200 \mathrm{~cm}^{-1}$ was dominated by the variable angle vibration of the $\mathrm{C}-\mathrm{H}$ bond. Two strong absorption peaks were observed at $1,200-1,000 \mathrm{~cm}^{-1}$, which are characteristic absorption peaks of $\alpha$ pyranosides [25]. The weak peak at around $873 \mathrm{~cm}^{-1}$ suggested a $\beta$-D-glucan, and a weak absorption peak at $804 \mathrm{~cm}^{-1}$ in the anomeric region $\left(950-700 \mathrm{~cm}^{-1}\right)$ suggested the existence of mannose [21].

\section{Determination of Molecular Weight}

The molecular weight $(\mathrm{Mw})$ and $\mathrm{Mw}$ distribution index were determined using a GPC-MALLS. The gel permeation chromatography result (Table 1 ) showed that the average Mw of rEPS414 was calculated to be $7.757 \times$ $10^{5} \mathrm{Da}$, in agreement with the previously reported molecular weight range of LAB EPS $\left(10^{4}-10^{6} \mathrm{Da}\right)$ [43]. The Mw distribution index was estimated to be 1.571, indicating the molar mass distribution of rEPS414 was relatively uniform. Previous studies showed that the biological activity of EPS is affected by its Mw and within a certain range; EPS of low and medium Mw appear to have stronger antioxidant and antitumor activities $[11,44]$.

\section{Monosaccharide Composition of rEPS}

The monosaccharide composition of rEPS414 was analyzed by HPLC. The peaks of pre-column derivatives of ten standard monosaccharides were determined in the order of mannose (11.669 $\mathrm{min})$, ribose $(14.950 \mathrm{~min})$, rhamnose (15.583 $\mathrm{min})$, glucuronic acid (17.685 $\mathrm{min})$, D-galacturonic acid (20.053 $\mathrm{min})$, glucose (23.242 $\mathrm{min})$, galactose (26.249 $\mathrm{min})$, xylose $(27.739 \mathrm{~min})$, arabinose $(28.768 \mathrm{~min})$, and fucose $(32.911 \mathrm{~min})$. Compared with the monosaccharide standards, purified rEPS was mainly composed of glucose. Small amounts of galactose, rhamnose, mannose, ribose, arabinose, and galacturonic acid were found in rEPS, and no fructose was detected. Previous studies have suggested that EPS with higher glucose contents have strong antitumor activity [45].

\section{D and 2D NMR Spectroscopy}

The structural features of purified rEPS were further identified and analyzed by ${ }^{1} \mathrm{H}$ NMR and ${ }^{13} \mathrm{C}$ NMR. In the ${ }^{1} \mathrm{H}$ NMR spectrum (Fig. 5A), anomeric proton signals were observed in downfield regions $(\delta 3.0-5.5 \mathrm{ppm})$, confirming the presence of polysaccharides. Fig. 5A shows that the integral ratios of the two regions of $\delta 4.8-5.6$ and $\delta$ 3.3-4.2 ppm may contain multiple monosaccharide structures, indicating that the rEPS is a heteropolysaccharide, which is consistent with the monosaccharide composition and FT-IR analysis results. In the ${ }^{1} \mathrm{H}$-NMR spectrum, the $\alpha$-type configuration generally appears at $\delta 4.8-5.6 \mathrm{ppm}$ and $\beta$-type configuration appears at $\delta 4.4-4.8 \mathrm{ppm}$ [46]. Hence, the signals at $\delta 5.33, \delta 5.32, \delta 4.91, \delta 4.90$, and $\delta 4.88 \mathrm{ppm}$ corresponded to the $\alpha$-glycosidic bond [47], whereas the signals at $\delta 4.57, \delta 4.56$, and $\delta 4.55 \mathrm{ppm}$ corresponded to the $\beta$-glycosidic bond. The proportion of $\alpha$-pyranose was much higher than that of $\beta$-pyranose, indicating that the rEPS sample contained mainly a-type glycosidic bonds. The strong peak at $\delta 4.70 \mathrm{ppm}$ was attributed to hydrogen-deuterium oxide, and other hydrogen signals were concentrated in the range of $\delta 3.33-4.16 \mathrm{ppm}$ and could not be resolved properly because of their overlapping chemical shifts. Furthermore, the signal at $\delta 1.2 \mathrm{ppm}$ corresponded to the terminal methyl, but it may have been pigment interference [48].

The chemical shift of the ${ }^{13} \mathrm{C}$ NMR spectrum was wider than that of the ${ }^{1} \mathrm{H}$ NMR spectrum and showed less overlap, giving higher resolution. In the ${ }^{13} \mathrm{C}$ NMR spectrum (Fig. $5 \mathrm{~B}$ ) of rEPS414, the region of $\delta 96-110 \mathrm{ppm}$ relfected the sugar end group chemical shift signal region, indicating that the sample contains $\alpha$-glucopyranose $(\delta$ 96-101 ppm) residues and $\beta$-glucopyranose $(\delta 101-110 \mathrm{ppm})$ residues. The resonance peaks of other carbon atoms were concentrated at the region of $\delta 60-87 \mathrm{ppm}$, and the peak at $\delta 82.31 \mathrm{ppm}$ was due to the presence of arabinose [49]. The peaks at $\delta 60-80 \mathrm{ppm}$ corresponded to galactose [50]. There was no obvious signal in the carboxylic signal region ( $\delta 170-180 \mathrm{ppm}$ ), indicating that the sample contains less uronic acid and glycoprotein [51], which is consistent with the UV and FT-IR analysis results. The signal in the region of $\delta 15-17 \mathrm{ppm}$ corresponds to the terminal methyl, or may be pigment interference [49]. Furthermore, a carbon signal appeared at $\delta 13 \mathrm{ppm}$, indicating that the rEPS sample contained rhamnose, which is consistent with the results of analyzing the monosaccharide composition.

\section{Microcosmic Morphology Analysis of rEPS}

As shown in Fig. 6, the SEM images of rEPS414 revealed a large number of scattered, fluffy, porous cellular network flake structures. This porous morphology indicates that the rEPS is beneficial for the diffusion of substances and metabolites required for cell growth. Its structure also showed that it has broad development and application prospects in terms of moisture retention and fragrance adsorption. 


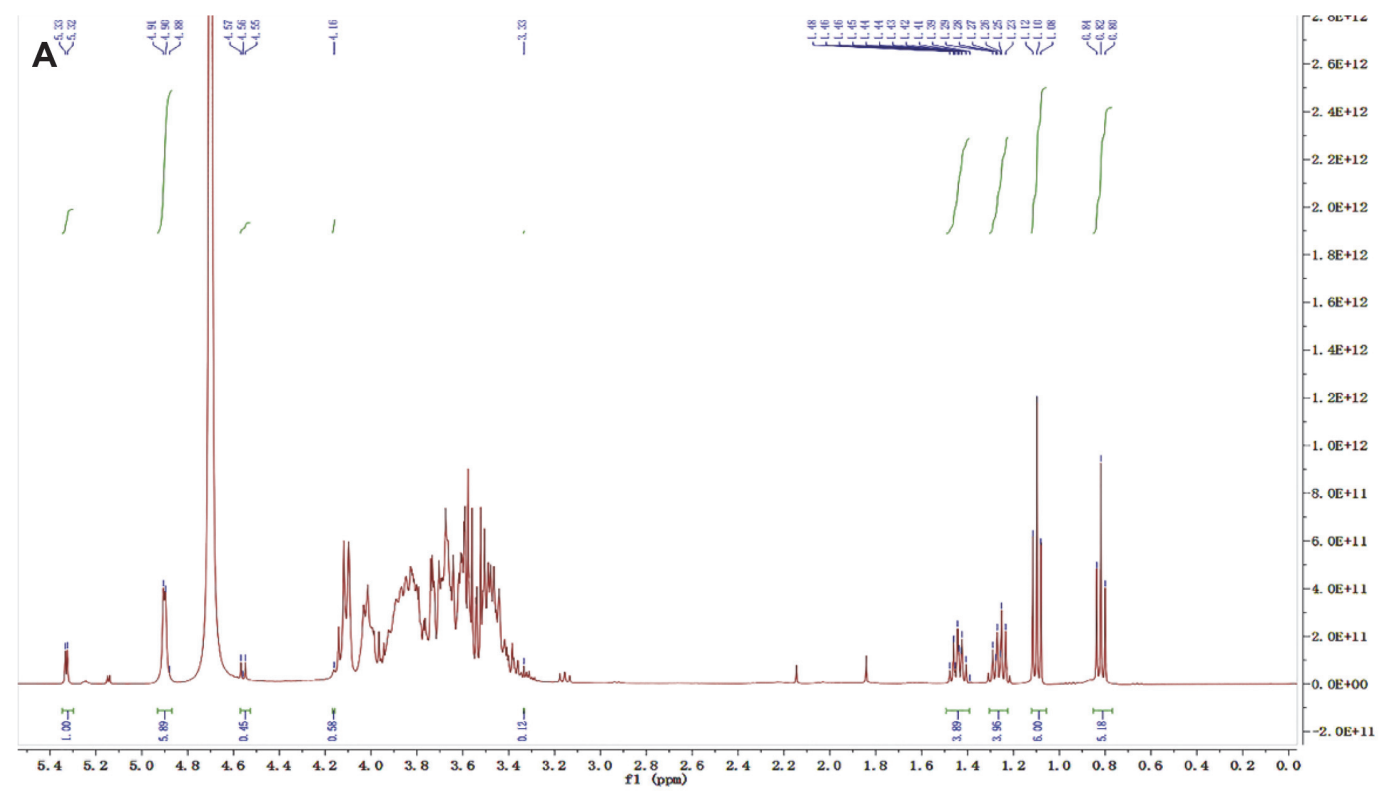

B

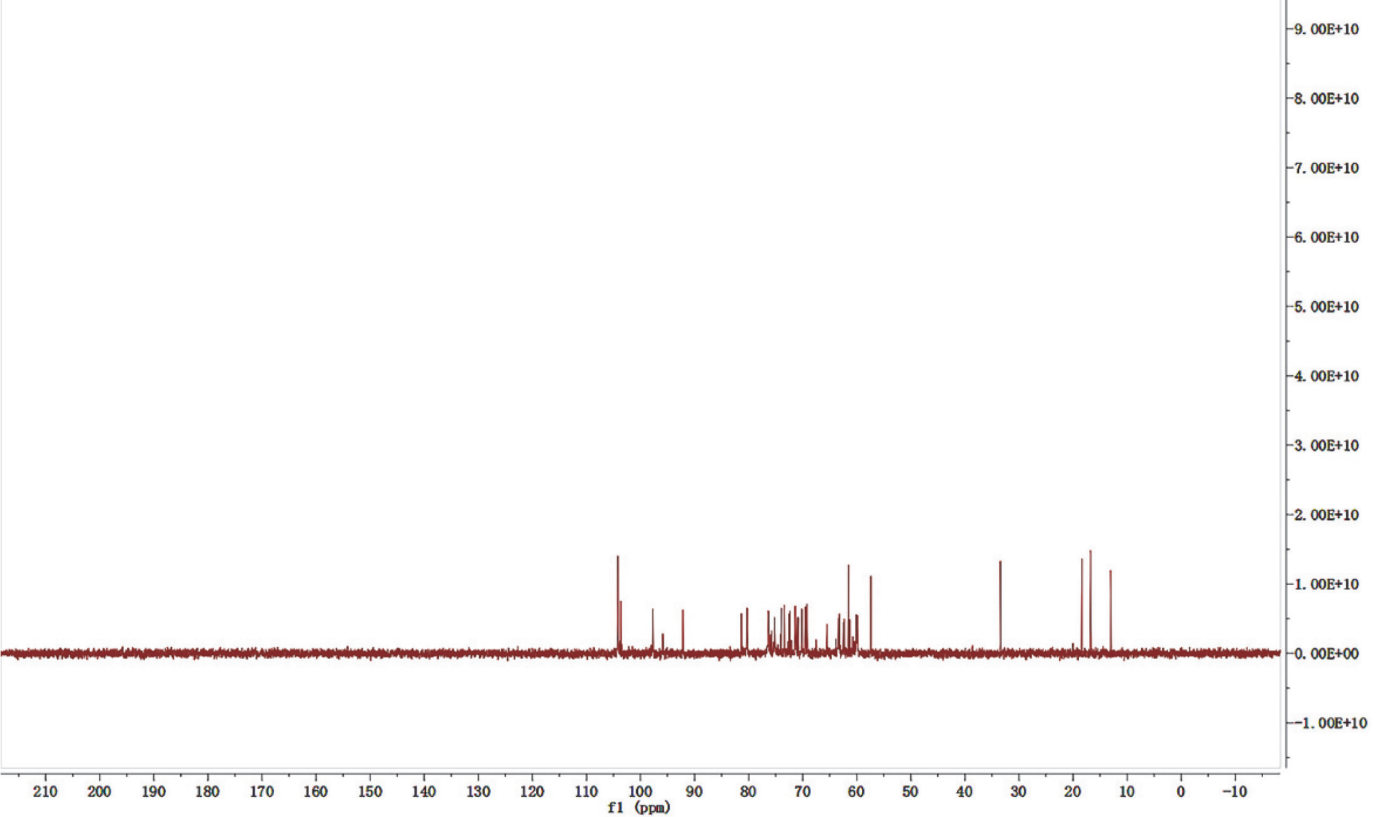

Fig. 5. ${ }^{1} \mathrm{H}$ NMR (A) and ${ }^{13} \mathrm{C}$ NMR (B) spectra of rEPS414.
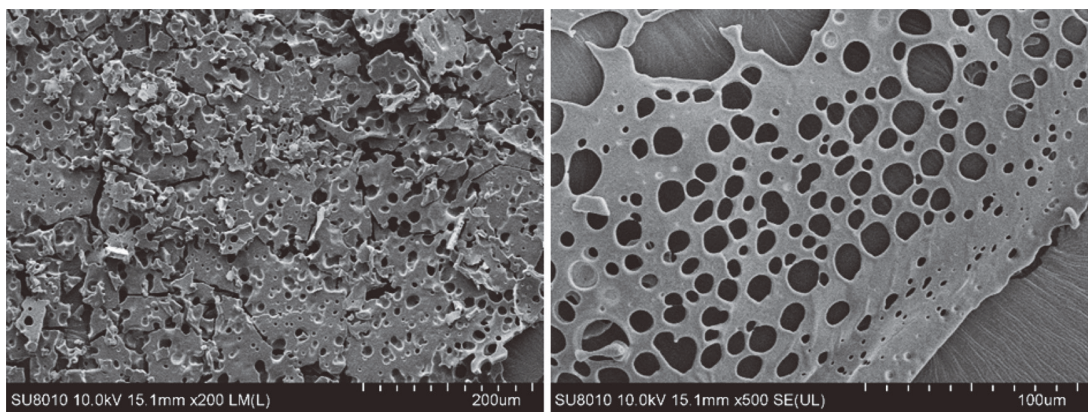

Fig. 6. Scanning electron microscopy images of rEPS414. 

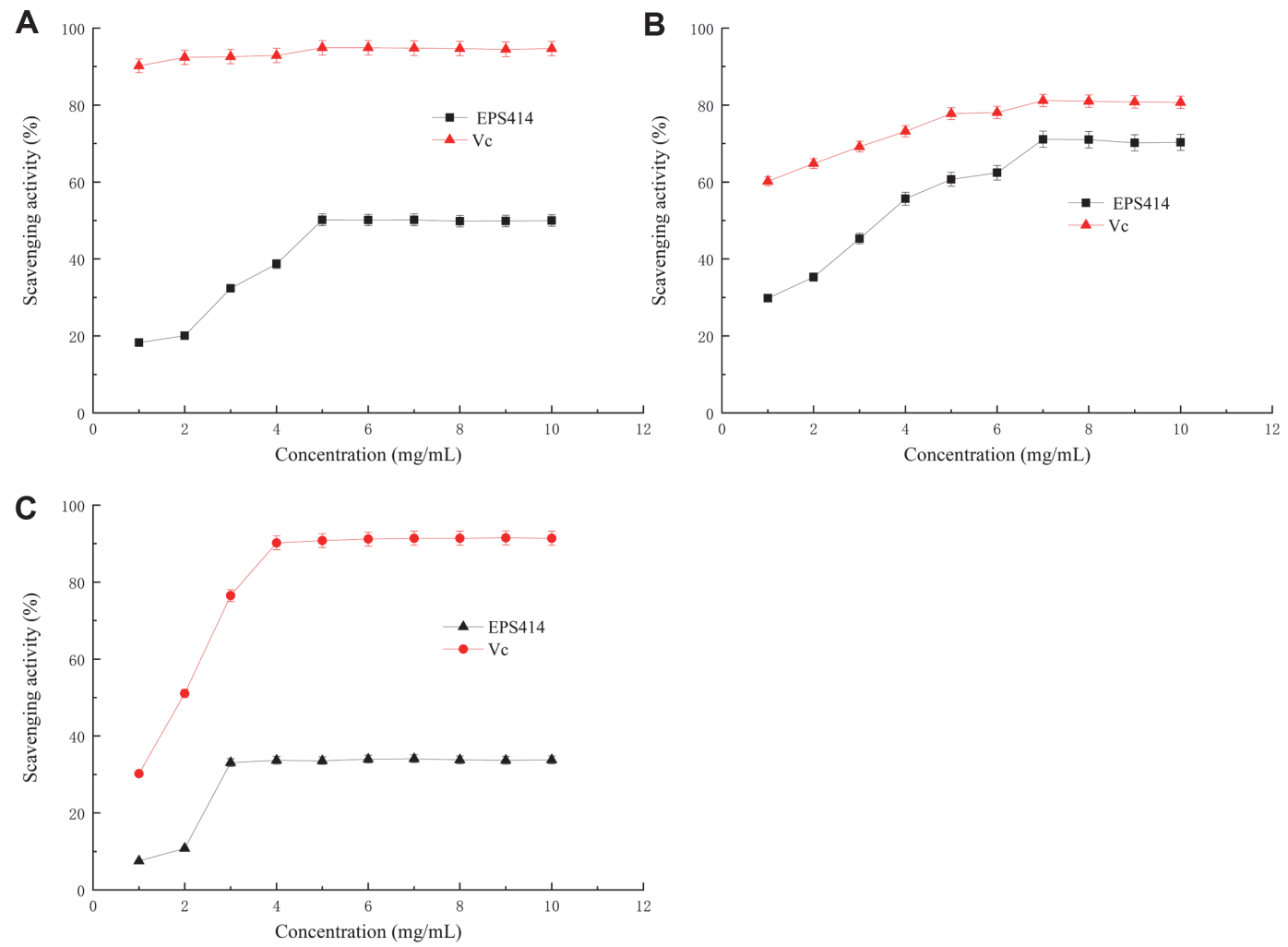

Fig. 7. In vitro antioxidant activity of rEPS414 from L. mesenteroides subsp. mesenteroides LM187 using ascorbic acid (Vc) as reference. (A) DPPH radical scavenging activity, (B) Hydroxyl radical scavenging activity, (C) Superoxide radical scavenging activity.

\section{Antioxidant Activity of rEPS}

DPPH radical has been widely used to determine the free radical scavenging activities of primary antioxidant activity; DPPH can accept electron or hydrogen radical to become a stable molecule [52]. The scavenging capacity of the rEPS sample for the DPPH free radical is shown in Fig. 7A; its scavenging capacity increased with increasing concentration in the range of $0-5 \mathrm{mg} / \mathrm{ml}$. When the concentration reached $5 \mathrm{mg} / \mathrm{ml}$, the $\mathrm{rEPS}$ and ascorbic acid scavenging activity reached maximum values of $50.2 \%$ and $94.9 \%$, respectively. Bomfim et al. [53] evaluated the antioxidant capacity of an EPS produced by L. plantarum CNPC003, revealing a DPPH scavenging activity of $40.72 \%$ at a concentration of $4 \mathrm{mg} / \mathrm{ml}$. Adesulu-Dahunsi et al. [8] also evaluated the antioxidant capacity of an EPS produced by Weissella cibaria GA44 and found DPPH scavenging activity of $48.9 \%$ at a concentration of $4 \mathrm{mg} / \mathrm{ml}$. Previous studies showed that the antioxidant activity of EPS is related to its molecular weight, monosaccharide composition, and glycoside type [54]. Furthermore, impurities such as proteins and pigments in EPS can influence the antioxidant activity [55]. Thus, the specific relevance of the DPPH radical scavenging activity of the rEPS requires further analysis.

Hydroxyl free radicals are the most reactive oxygen free radicals and can react with a variety of biological macromolecules in living cells in various manners, such as by inducing lipid peroxidation and causing DNA damage. Therefore, scavenging hydroxyl free radicals is an effective approach for preventing oxidative damage to cells and tissues [56]. Some EPS isolated from LAB (such as lactobacillus) were reported to have good hydroxyl free radical scavenging activities $[57,58]$. As shown in Fig. 7B, the scavenging activities of rEPS414 against hydroxyl radicals gradually increased with the concentration of polysaccharides in the range of $0-10 \mathrm{mg} / \mathrm{ml}$, but its scavenging activities were lower than that of ascorbic acid. At a concentration of $7 \mathrm{mg} / \mathrm{ml}$, the rEPS sample scavenging activity reached a maximum value of $71.0 \%$, which is close to that of Vc (81.0\%). Wang et al. [25] evaluated the antioxidant capacity of an EPS produced by Lactobacillus fermentum and observed a lower hydroxyl scavenging activity of $61.67 \%$ at a concentration of $4 \mathrm{mg} / \mathrm{ml}$ compared to that found in the present study. These results suggest that the rEPS has good hydroxyl radical scavenging activity. Previous studies reported that the scavenging activity of EPS for hydroxyl radicals occurred via inhibition of hydroxyl radical generation by chelating $\mathrm{Fe}^{2+}$ or $\mathrm{Cu}^{+}$, which are powerful pro-oxidants with important roles in catalytic oxidation reactions $[59,60]$.

Superoxide radicals can react with biological macromolecules and cause tissue damage. They can also promote the generation of other reactive oxygen species, such as hydrogen peroxide, hydroxyl radical, and singlet oxygen, which induce strong oxidative toxicity to cells [60,61]. As shown in Fig. 7C, at different concentrations of 0-3 mg/ $\mathrm{ml}$, the purified rEPS displayed varying degrees of antioxidant activity in a dose-dependent manner, similar to its scavenging activity trend for DPPH free radicals. However, there was no obvious concentration dependence in the 
range of 3-10 $\mathrm{mg} / \mathrm{ml}$. At a concentration of $3 \mathrm{mg} / \mathrm{ml}$, the EPS scavenging activity reached a maximum value of $33.1 \%$, but the scavenging activities of the rEPS were lower than that of ascorbic acid. Scavenging capacity may be ascribed to the direct contact of EPS molecules with superoxide radical to form stable radicals, which may terminate the radical chain reaction [62].

The results of antioxidant activity analysis in vitro demonstrate that rEPS414 from L. mesenteroides subsp. mesenteroides LM187 has potential to be developed as a natural antioxidant or functional food additive.

\section{Conclusion}

In the present study, a rEPS-producing strain (LM187) isolated from Sichuan paocai demonstrated a strong ability to survive under acid and bile salt conditions and to lower cholesterol. Purification, structural characterization, and in vitro antioxidant activities of rEPS from strain LM187 were analyzed. The results show that strain LM187 can produce rEPS and has potential as a probiotic. rEPS produced by L. mesenteroides subsp. mesenteroides LM187 is mainly composed of glucose with an average Mw of $7.757 \times 10^{5} \mathrm{Da}$. The purified rEPS exhibited a typical polysaccharide absorption pattern and displayed a strong ability to scavenge radicals. These results indicate that strain LM187 is a promising probiotic for use in industry.

\section{Acknowledgments}

This work was supported by the Science and Technology Support Project of Sichuan Province (Grant no. 2019ZYZF0170); the Foundation of Education Department of Sichuan Province (Grant no. 18ZA0447); and the Young Scholars Program of Xihua University.

\section{Conflict of Interest}

The authors have no financial conflicts of interest to declare.

\section{References}

1. LeBlanc JG, Milani C, de Giori GS, Sesma F, van Sinderen D, Ventura M. 2013. Bacteria as vitamin suppliers to their host: a gut microbiota perspective. Curr. Opin. Biotechnol. 24: 160-168.

2. Zhu Y, Wang X, Pan W, Shen X, He Y, Yin H, et al. 2019. Exopolysaccharides produced by yogurt-texture improving lactobacillus plantarum RS20D and the immunoregulatory activity. Int. J. Biol. Macromol. 121:342-349.

3. Laiño J, Villena J, Kanmani P, Kitazawa H. 2016. Immunoregulatory effects triggered by lactic acid bacteria exopolysaccharides: new insights into molecular interactions with host cells. Microorganisms 4: 27.

4. Moslehi-Jenabian S, Lindegaard L, Jespersen L. 2010. Beneficial effects of pobiotic and food borne yeasts on human health. Nutrients 2: $449-473$.

5. Jin H, Jeong Y, Yoo SH, Johnston TV, Ku S, Ji GE. 2019. Isolation and characterization of high exopolysaccharide-producing Weissella confusa VP30 from young children's feces. Microb. Cell Fact. 18: 110.

6. Vinogradov E, Sadovskaya I, Grard T, Chapot-Chartier MP. 2016. Structural studies of the rhamnose-rich cell wall polysaccharide of Lactobacillus casei BL23. Carbohydr. Res. 435: 156-161.

7. Rajoka MSR, Mehwish HM, Hayat HF, Hussain N, Sarwar S, Aslam H, et al. 2019. Characterization, the antioxidant and antimicrobial activity of exopolysaccharide isolated from poultry origin lactobacilli. Probiotics Antimicrob. Proteins 11: 1132-1142.

8. Adesulu-Dahunsi AT, Sanni AI, Jeyaram K. 2018. Production, characterization and in vitro antioxidant activities of exopolysaccharide from Weissella cibaria GA44. L.W.T. Food Sci. Technol. 87: 432-442.

9. You X, Yang L, Zhao X, Ma K, Chen X, Zhang C, et al. 2020. Isolation, purification, characterization and immunostimulatory activity of an exopolysaccharide produced by Lactobacillus pentosus LZ-R-17 isolated from Tibetan kefir. Int. J. Biol. Macromol. 158: 408-419.

10. Ryan PM, Stolte EH, London LEE, Wells JM, Long SL, Joyce SA, et al. 2019. Lactobacillus mucosae DPC 6426 as a bile-modifying and immunomodulatory microbe. BMC Microbiol. 19: 33

11. Di W, Zhang L, Wang S, Yi H, Han X, Fan R, et al. 2017. Physicochemical characterization and antitumour activity of exopolysaccharides produced by Lactobacillus casei SB27 from yak milk. Carbohydr. Polym. 171: 307-315.

12. Li W, Xia X, Tang W, Ji J, Rui X, Chen X, et al. 2015. Structural characterization and anticancer activity of cell-bound exopolysaccharide from Lactobacillus helveticus MB2-1. J. Agric. Food Chem. 63: 3454-3463.

13. Ibarburu I, Puertas AI, Berregi I, Rodríguez-Carvajal MA, Prieto A, Dueñas MT. 2015. Production and partial characterization of exopolysaccharides produced by two Lactobacillus suebicus strains isolated from cider. Int. J. Food Microbiol. 214: 54-62.

14. Olivares-Illana V, Lopez-Munguia A, Olvera C. 2003. Molecular characterization of inulosucrase from Leuconostoc citreum: a fructosyltransferase within a glucosyltransferase. J. Bacteriol. 185: 3606-3612.

15. Rehman R, Wang Y, Wang J, Geng W. 2018. Physicochemical analysis of Mozzarella cheese produced and developed by the novel EPS-producing strain Lactobacillus kefiranofaciens ZW3. Int. J. Dairy Technol. 71: 90-98.

16. Cao J, Yang J, Hou Q, Xu H, Zheng Y, Zhang H, et al. 2017. Assessment of bacterial profiles in aged, home-made Sichuan paocai brine with varying titratable acidity by PacBio SMRT sequencing technology. Food Control. 78: 14-23.

17. Liu T, Zhou K, Yin S, Liu S, Zhu Y, Yang Y, et al. 2019. Purification and characterization of an exopolysaccharide produced by Lactobacillus plantarum HY isolated from home-made Sichuan Pickle. Int. J. Biol. Macromol. 134: 516-526.

18. Hu X, Pang X, Wang PG, Chen M. 2019. Isolation and characterization of an antioxidant exopolysaccharide produced by Bacillus sp. S-1 from Sichuan pickles. Carbohydr. Polym. 204: 9-16.

19. Miao M, Bai A, Jiang B, Song Y, Cui SW, Zhang T. 2014. Characterisation of a novel water-soluble polysaccharide from Leuconostoc citreum SK24.002. Food Hydrocoll. 36: 265-272.

20. Vinderola CG, Reinheimer JA. 2003. Lactic acid starter and probiotic bacteria: a comparative "in vitro" study of probiotic characteristics and biological barrier resistance. Food Res. Int. 36: 895-904

21. Dilna SV, Surya H, Aswathy RG, Varsha KK, Sakthikumar DN, Pandey A, Nampoothiri KM. 2015. Characterization of an exopolysaccharide with potential health-benefit properties from a probiotic Lactobacillus plantarum RJF4. L. W.T. Food Sci. Technol. 64: 1179-1186.

22. Mirlohi M, Madany G, Hassanzade A. Yahay MJ. 2011. On the colorimetric method for cholesterol determination in the laboratory media. Int. J. Biol. Chem. 6: 37-41

23. Savadogo A, Ouattara CAT, Savadogo PW, Barro N, Ouattara AS, Traore AS. 2003. Identification of exopolysaccharides-producing lactic acid bacteria from Burkina Faso fermented milk samples. Afr. J. Biotechnol. 3: 189-194. 
24. Rühmann B, Schmid J, Sieber V. 2015. Methods to identify the unexplored diversity of microbial exopolysaccharides. Front. Microbiol. 6: 565

25. Wang K, Niu M, Song D, Song X, Zhao J, Wu Y, et al. 2020. Preparation, partial characterization and biological activity of exopolysaccharides produced from Lactobacillus fermentum S1. J. Biosci. Bioeng. 129: 206-214.

26. Xue BL, Wen JL, Xu F, Sun RC. 2012. Structural characterization of hemicelluloses fractionated by graded ethanol precipitation from Pinus yunnanensis. Carbohydr. Res. 352: 159-165.

27. Li C, Fu X, Luo F, Huang Q. 2013. Effects of maltose on stability and rheological properties of orange oil-in-water emulsion formed by OSA modified starch. Food Hydrocoll. 32: 79-86.

28. Wang L, Liu F, Wang A, Yu Z, Xu Y, Yang Y. 2017. Purification, characterization and bioactivity determination of a novel polysaccharide from pumpkin (Cucurbita moschata) seeds. Food Hydrocoll. 66: 357-364.

29. Rai AK, Jini R, Swapna HC, Sachindra NM, Bhaskar N, Baskaran V. 2011. Application of native lactic acid bacteria (LAB) for fermentative recovery of lipids and proteins from fish processing wastes: bioactivities of fermentation products. J. Aquat. Food Prod. Technol. 20: 32-44.

30. Xia Z. 2015. Preparation of the oligosaccharides derived from Flammulina velutipes and their antioxidant activities. Carbohydr. Polym. 118: 41-43.

31. Feng K, Chen W, Sun L, Liu J, Zhao Y, Li L, et al. 2015. Optimization extraction, preliminary characterization and antioxidant activity in vitro of polysaccharides from Stachys sieboldii Miq. Tubers. Carbohydr. Polym. 125: 45-52.

32. Sawa N, Okamura K, Zendo T, Himeno K, Nakayama J, Sonomoto K. 2010. Identification and characterization of novel multiple bacteriocins produced by Leuconostoc pseudomesenteroides QU15. J. Appl. Microbiol. 109: 282-291.

33. Shevtsov AB, Kushugulova AR, Kojakhmetov SS, Oralbaeva SS, Stoyanova LG, Abzhalelov AB, et al. 2011. Detection of Lactobacillus species using a gene fragment of the RNA polymerase beta subunit rpoB. Moscow Univ. Biol. Sci. Bull. 66: 22-27.

34. Angmo K, Kumari A, Savitri, Bhalla TC. 2016. Probiotic characterization of lactic acid bacteria isolated from fermented foods and beverage of Ladakh. LWT Food Sci. Technol. 66: 428-435.

35. Song M, Yun B, Moon JH, Park DJ, Lim K, Oh S. 2015. Characterization of selected Lactobacillus strains for use as probiotics. Korean J. Food Sci. Anim. Resour. 35: 551-556.

36. Guo XH, Kim JM, Namb HM, Park SY, Kim JM. 2010. Screening lactic acid bacteria from swine origins for multistrain probiotics based on in vitro functional properties. Anaerobe 16: 321-326.

37. Succi M, Tremonte P, Reale A, Sorrentino E, Grazia L, Pacifico S, et al. 2005. Bile salt and acid tolerance of Lactobacillus rhamnosus strains isolated from Parmigiano Reggiano cheese. FEMS Microbiol. Lett. 244: 129-137.

38. Nami Y, Panahi B, Jalaly HM, Bakhshayesh RV, Hejazi MA. 2020. Application of unsupervised clustering algorithm and heat-map analysis for selection of lactic acid bacteria isolated from dairy samples based on desired probiotic properties. L.W.T. Food Sci. Technol. 118: 108839.

39. Lee S, Kim M. 2019. Leuconostoc mesenteroides MKSR isolated from kimchi possesses a-glucosidase inhibitory activity, antioxidant activity, and cholesterol-lowering effects. LWT. 116: 108570.

40. Bhat B, Bajaj BK. 2018. Hypocholesterolemic and bioactive potential of exopolysaccharide from a probiotic Enterococcus faecium K1 isolated from kalarei. Bioresour. Technol. 254: 264-267.

41. Wang J, Zhao X, Yang Y, Zhao A, Yang Z. 2015. Characterization and bioactivities of an exopolysaccharide produced by Lactobacillus plantarum YW32. Int. J. Biol. Macromol. 74: 119-126.

42. Saravanan C, Shetty PKH. 2016. Isolation and characterization of exopolysaccharide from Leuconostoc lactis KC117496 isolated from idli batter. Int. J. Biol. Macromol. 90: 100-106.

43. Wang K, Li W, Rui X, Chen X, Jiang M, Dong M. 2014. Characterization of a novel exopolysaccharide with antitumor activity from Lactobacillus plantarum 70810. Int. J. Biol. Macromol. 63: 133-139.

44. Sun L, Wang L, Li J, Liu H. 2014. Characterization and antioxidant activities of degraded polysaccharides from two marine Chrysophyta. Food Chem. 160: 1-7.

45. Zheng JQ, Mao XJ, Geng LJ, Yang GM, Xu CP. 2014. Production optimization, preliminary characterization and bioactivity of exopolysaccharides from Incutis tamaricis (Pat.) Fiasson \& Niemela. J. Taiwan Inst. Chem. Eng. 45: 725-733.

46. Rani RP, Anandharaj M, Sabhapathy P, Ravindran AD. 2017. Physiochemical and biological characterization of novel exopolysaccharide produced by Bacillus tequilensis FR9 isolated from chicken. Int. J. Biol. Macromol. 96: 1-10.

47. Das D, Goyal A. 2014. Characterization and biocompatibility of glucan: a safe food additive from probiotic Lactobacillus plantarum DM5. J. Sci. Food Agric. 94: 683-690.

48. Yu XH, Liu Y, Wu XL, Liu LZ, Fu W, Song DD. 2017. Isolation, purification, characterization and immunostimulatory activity of polysaccharides derived from American ginseng. Carbohydr. Polym. 156: 9-18.

49. Walia M, Sharma U, Bhushan S, Kumar N, Singh B. 2013. Arabinan-type polysaccharides from industrial apple pomace waste. Chem. Nat. Compd. 49: 794-798.

50. Wu Y, Hu N, Pan Y, Zhou L, Zhou X. 2007. Isolation and characterization of a mannoglucan from edible Cordyceps sinensis mycelium. Carbohydr. Res. 342: 870-875.

51. Wang L, Liu HM, Qin GY. 2017. Structure characterization and antioxidant activity of polysaccharides from Chinese quince seed meal. Food Chem. 234: 314-322.

52. Xu YM, Cui YL, Wang X, Yue FF, Shan YY, Liu BF, et al. 2019. Purification, characterization and bioactivity of exopolysaccharides produced by Lactobacillus plantarum KX041. Int. J. Biol. Macromol. 128: 480-492.

53. Bomfim VB, Neto JHPL, Leite KS, Vieira ÉDA, Iacomini M, Silva CM, Santos KMOD, et al. 2020. Partial characterization and antioxidant activity of exopolysaccharides produced by Lactobacillus plantarum CNPC003. LWT. 127: 109349.

54. Jiang C, Wang M, Liu J, Gan D, Zeng X. 2011. Extraction, preliminary characterization, antioxidant and anticancer activities in vitro of polysaccharides from Cyclina sinensis. Carbohydr. Polym. 84: 851-857.

55. Zhu HJ, Tian L, Zhang L, Bi JX, Song QQ, Yang H, et al. 2018. Preparation, characterization and antioxidant activity of polysaccharide from spent Lentinus edodes substrate. Int. J. Biol. Macromol. 112: 976-984.

56. Wu S, Huang X. 2017. Preparation and antioxidant activities of oligosaccharides from Crassostrea gigas. Food Chem. 216: $243-246$.

57. Tang W, Dong M, Wang W, Han S, Rui X, Chen X, et al. 2017. Structural characterization and antioxidant property of released exopolysaccharides from Lactobacillus delbrueckii ssp. bulgaricus SRFM-1. Carbohydr. Polym. 173: 654-664.

58. Min WH, Fang XB, Wu T, Fang L, Liu CL, Wang J. 2019. Characterization and antioxidant activity of an acidic exopolysaccharide from Lactobacillus plantarum JLAU103. J. Biosci. Bioeng. 127: 758-766.

59. Liu CH, Wang CH, Xu ZL, Wang Y. 2007. Isolation, chemical characterization and antioxidant activities of two polysaccharides from the gel and the skin of Aloe barbadensis Miller irrigated with sea water. Process Biochem. 42: 961-970.

60. Wang X, Shao C, Liu L, Guo X, Xu Y, Lv X. 2017. Optimization, partial characterization and antioxidant activity of an exopolysaccharide from Lactobacillus plantarum KX041. Int. J. Biol. Macromol. 103: 1173-1184.

61. Fan J, Feng H, Yu Y, Sun M, Liu Y, Li T, et al. 2017. Antioxidant activities of the polysaccharides of Chuanminshen violaceum. Carbohydr. Polym. 157: 629-636.

62. Lin C, Wang C, Chang S, Inbaraj BS, Chen B. 2009. Antioxidative activity of polysaccharide fractions isolated from Lycium barbarum Linnaeus. Int. J. Biol. Macromol. 45: 146-151. 